\title{
Revitalization of frozen autologous bone graft using adipose-derived stem cells
}

\author{
Aoki $Y^{1}$, Yamamoto $N^{1 *}$, Hayashi $K^{1}$, Sugimoto $N^{2}$, Kimura $H^{1}$, Takeuchi $A^{1}$, Miwa $S^{1}$, Igarashi $K^{1}$, Inatani $H^{1}$, Higuchi $T^{1}$, Abe $K^{1}$, Taniguchi \\ $\mathbf{Y}^{1}$, Araki $\mathbf{Y}^{1}$ and Tsuchiya $\mathbf{H}^{1}$ \\ ${ }^{1}$ Department of Orthopaedic Surgery, Graduate School of Medical Sciences, Kanazawa University, Japan \\ ${ }^{2}$ Department of Physiology, Graduate School of Medical Sciences, Kanazawa University, Japan
}

\begin{abstract}
Adipose-derived stem cells (ADSCs) are pluripotent stem cells and have multipotentiality equivalent to bone marrow-derived stem cells. We examined the ability of ADSCs to revitalize frozen bone toward clinical application. In a conditioned culture method, proliferation and signaling pathways (Smad and JNK) of osteoblasts affected by ADSCs were examined using cell proliferation and Western blotting assays, and they were significantly enhanced. In addition, in a coculture method, the gene expression levels (BMP2 and ALP1) of osteoblasts affected by ADSCs were determined using real-time reverse transcription polymerase chain reaction (RTPCR) and they were significantly less. Therefore, both of the methods confirmed osteoblast differentiation and osteogenesis-promoting action of ADSCs. Next, the femoral shafts of 20 rats were excised, frozen in liquid nitrogen, and then reimplanted as an autologous bone transplant. The models were divided into groups with $(n$ $=10)$ and without $\operatorname{ADSCs}(n=10)$. Histopathologic examination was performed to assess its revitalization ability, and bone revitalization was observed significantly more with than without ADSCs in week 8. The osteogenesis-promoting action of ADSCs for frozen bone was suggested. Using ADSCs to promote revitalization of frozen bone is expected in the future.
\end{abstract}

\section{Introduction}

Various methods exist for reconstruction after resection of malignant bone tumor, including recycling of the autograft, for example autoclaved, Pasteur, or irradiated autografts. Since 1999, we developed and have clinically applied a novel method of biological reconstruction using tumor-bearing autografts treated with liquid nitrogen [1]. Apart from autograft recycling, for example for simplicity and perfect fit, no propagation of pathogens, or no allergic reaction, the use of liquid nitrogen presents several advantages. It has good osteoinduction and osteoconduction potential, allows for easy attachment of soft tissue and cryoimmunology, and provides sufficient bone stock and mechanical hardness [1-4]. However, frozen bone is a useful alternative for biological reconstruction of bone defects post-tumor resection, as revitalization of bone following a transplant requires a long time. Delayed bone union was the main problem in biological reconstruction cases, and frozen autograft is used less often than autoclaved, irradiated, and Pasteur autografts. We reported a host bone-frozen bone union seen at a mean of 6.2 months postoperatively among the long-term outcomes of using frozen autografts [5]. However, we experienced some delayed bone unions after using frozen autograft, and some of these cases required a second surgery. We aimed to achieve bone revitalization and improvement of a host bone-frozen bone union to overcome delayed bone union. For example, we used a hemicortical resection method to preserve more host bone in some cases if we could preserve the contralateral cortex of the lesion during bone tumor resection. Furthermore, we developed a new technique of reconstruction using the pedicle freezing method. These techniques allowed the autografts to obtain a greater amount of protein through blood [6,7]. Further treatments that would allow rapid bone revitalization are desirable, and we sought a nontechnological method to promote revitalization of frozen bone. We focused on stem cell therapy and particularly on adipose-derived stem cells (ADSCs).

Stem cell therapy uses pluripotent stem cells, such as embryonic (ES) and induced pluripotent (iPS) stem cells, and multipotent stem cells, such as hematopoietic and mesenchymal stem cells. Mesenchymal stem cells have different characteristics based on the tissue to be collected. They are also called bone marrow-derived stem cells (BMSCs), ADSCs, and so forth based on the tissue to be collected. BMSCs have been validated in the regenerative medicine area for a long time [8]. However, since fewer cells are obtained by one sampling and the sampling method is invasive, clinical application is not easy. ADSCs have multipotentiality equivalent to BMSCs. Additionally, as large volumes of adipose tissue can be collected easily, ADSCs can be obtained in large quantities [9]. The group of cells collected from adipose tissue with collagenase is called the stromal vascular fraction and includes endothelial cells, fibroblasts, white blood cells, and ADSCs. ADSCs can be readily harvested in large numbers from low donor sites. Seki et al. [10] reported that injected ADSCs can repair and restore the function of the impaired liver in cirrhosis. Furuichi et al. [11] reported that injection of ADSCs reduced acute tubular necrosis in the injured kidney. ADSCs are beneficial for regeneration and repair of various injured tissue. We are also conducting research on

${ }^{*}$ Correspondence to: Norio Yamamoto, Department of Orthopaedic Surgery, Graduate School of Medical Sciences, Kanazawa University, 13-1 Takaramachi, Kanazawa, Japan, E-mail: norinori@med.kanazawa-u.ac.jp

Key words: adipose-derived stem cells, animal models, frozen autologous bone graft, osteoblast, revitalization

Received: February 25, 2019; Accepted: March 18, 2019; Published: March 21, 2019 
tissue regeneration using the stromal vascular fraction and ADSCs and have so far reported some studies, for example, studies on distraction osteogenesis [12], peripheral nerve [13], osteoarthritis [14], ADSCs sheet [15], meniscus [16], tendon-bone [17], and atypical lipomatous tumors [18]. Lee et al. [19] reported that ADSCs promote bone union after fracture. It was considered that ADSCs promote not only bone formation, but also revitalization. We examined the use of the stromal vascular fraction and ADSCs for tissue regeneration, specifically the ability of ADSCs to revitalize frozen bone in vitro and in vivo for clinical application. The humoral factors of growth and differentiation from ADSCs to osteoblasts were evaluated in vitro. Bone revitalization of frozen autograft-added ADSCs were evaluated in vivo.

\section{Materials and methods}

\section{Cell culture of ADSCs}

ADSCs were isolated according to a modification of a previously reported method as described below $[16,20]$. In brief, we harvested adipose tissue from the inguinal subcutaneous layer of 10-week-old Wistar rats (Japan SLC Co., Shizuoka, Japan), and the adipose tissue was washed with phosphate-buffered saline (PBS; Wako, Osaka, Japan). We pasted the adipose tissue after cutting it for 5 minutes using scissors. Type I collagenase (Wako) was dissolved in PBS to achieve $0.12 \%$ in $20 \mathrm{~mL}$ and was used for digesting adipose tissue in a water bath at $37^{\circ} \mathrm{C}$ for 45 minutes. The adipose tissue mixture was agitated every 15 minutes while digesting. Immediately after digestion was completed, we added $20 \mathrm{~mL}$ Dulbecco's modified Eagle's medium (DMEM; Wako) containing 10\% fetal bovine serum (FBS; Nichirei Biosciences, Inc., Tokyo, Japan), 100 units/mL penicillin, and $100 \mu \mathrm{g} / \mathrm{mL}$ streptomycin (P/S; Wako), and neutralized the collagenase activity. We filtered the obtained aqueous solution twice (Cell Strainer, BD Falcon, Tewksbury, MA, USA) and collected it in a tube. We centrifuged the filtrate at 1500 revolutions per minute (rpm) for 5 minutes at $25^{\circ} \mathrm{C}$ and removed the supernatant. Next, we added a pellet of ADSCs at $5 \times 10^{4} \mathrm{cells} / \mathrm{cm}^{2}$ in $100 \mathrm{~mm}$ tissue culture dishes (TPP, Trasadingen, Switzerland) and ADSCs were cultured with complete medium, same concentration as of DMEM, including FBS and P/S. After culture for 1 week, the cells were subcultured, harvested with $0.25 \%$ trypsin-ethylenediaminetetraacetic acid (EDTA; Wako), and were centrifuged at $1000 \mathrm{rpm}$ for 5 minutes. These cells were cultured in the medium at $37^{\circ} \mathrm{C}$ in a humidified atmosphere of $5 \% \mathrm{CO}_{2}$, and the media were changed every 3 days in 1 week. These cells were subcultured every week, and the passage of 3 ADSCs after washing twice with PBS was used for the conditioned culture and coculture methods in vitro and for addition in vivo.

\section{Cell harvest and culture of osteoblasts}

We purchased primary rat osteoblasts, isolated from SpragueDawley (SD) rat calvaria, from Primary Cell from Cosmo Bio Co. Ltd. (Sapporo, Hokkaido, Japan), and cultured them in phenol red-free a-minimal essential medium (aMEM; Wako) containing 10\% FBS, 100 units $/ \mathrm{mL}$ penicillin, and $100 \mu \mathrm{g} / \mathrm{mL}$ streptomycin $(\mathrm{P} / \mathrm{S})$ in a humidified atmosphere of $5 \% \mathrm{CO}_{2}$ at $37^{\circ} \mathrm{C}$ in $100 \mathrm{~mm}$ tissue culture dishes (TPP), and the media were changed every 3 days in 1 week. These cells were subcultured every week, and the passage of three osteoblasts after washing twice with PBS was used for the conditioned culture and coculture methods in vitro.

\section{In vitro experiments}

In the in vitro experimental model, to ascertain the paracrine effect of ADSCs for osteoblast cells, we used the conditioned culture and coculture methods. We performed cell proliferation and Western blotting assays using the conditioned cultured method, and real-time RT-PCR assays using the coculture method.

\section{Conditioned cultured method}

Conditioned medium of osteoblast cells and ADSCs was obtained as follows. Briefly, $1.0 \times 10^{6}$ osteoblasts and ADSCs were plated on 100 $\mathrm{mm}$ tissue culture dishes and incubated in complete growth medium containing serum until the cells reach the appropriate cell density. The medium was removed and was washed gently with PBS twice. After PBS was removed and the medium without serum gently added, these cells were incubated for 1 day. Then, we transferred the medium to a centrifuge tube and centrifuged at $1500 \mathrm{rpm}$ at $4^{\circ} \mathrm{C}$ for 10 minutes. The supernatant was dispensed quickly into a new tube that had been previously cooled.

\section{Cell proliferation assay}

We analyzed cell proliferation and viability using the Cell Counting Kit-8 (Wako) as described previously [21,22]. A total of 100,000 osteoblasts were seeded in 96-well plates (TPP) and incubated in the prepared conditioned culture media of osteoblasts (control group) and ADSCs (ADSCs group). After 3 days, the cells were incubated with WST-8 (4-[3-(4-iodophenyl)-2-(4-nitrophenyl)-2H-5-tetrazolio]-1,3benzene disulfonate; $10 \mu \mathrm{L}$ WST- 8 in $100 \mu \mathrm{L}$ medium) for 3 hours at $37^{\circ} \mathrm{C}$. We recorded the absorbance of the colored formazan product produced by mitochondrial dehydrogenases in metabolically active cells at $450 \mathrm{~nm}$ using iMark ${ }^{\text {ri }}$ Microplate Absorbance Reader (Bio-Rad Laboratories, Hercules, CA, USA) as the background value. Osteoblast proliferation affected by ADSCs was compared between the control and ADSCs groups.

\section{Western blotting assays}

One million osteoblasts and ADSCs were plated in $10 \mathrm{~cm}$ tissue culture dishes and incubated in complete growth medium containing serum until the cells reached the appropriate cell density. The medium was removed and was gently washed with PBS twice. After PBS was removed and medium without serum gently added, these cells were incubated for 6 hours. The medium was removed and was gently washed with PBS twice. After PBS was removed, we gently added the prepared conditioned medium of osteoblast cells (control group) and ADSCs (ADSCs group). Furthermore, these cells were incubated for 20 minutes.

We performed Western blotting analyses as described previously $[21,23]$. Briefly, we used $10 \%$ sodium dodecyl sulfate-polyacrylamide gel electrophoresis (SDS-PAGE) to separate the same amounts of protein. We transferred separated proteins onto membranes of polyvinylidene fluoride, and they were subsequently incubated with primary antibodies (1:1000), followed by incubation with horseradish peroxidase (HRP)linked secondary antibodies (1:2000). We used Immobilon Western Chemiluminescent HRP Substrate (Millipore, Billerica, MA, USA) to develop the blots.

\section{Materials}

Phospho-Smad1/5 (Ser463/465; 41D10) rabbit monoclonal antibodies (mAb), Smad1 rabbit mAb, phospho-SAPK/JNK (Thr183/ Thr185; 81E11) rabbit $\mathrm{mAb}$, SAPK/JNK rabbit $\mathrm{mAb}$, and horseradish peroxidase-conjugated anti-rabbit IgG (\#7074); they were purchased from Cell Signaling Technology, Inc. (Danvers, MA, USA). 


\section{Cocultured method}

The noncontact coculture was established between ADSCs $(1.0 \times$ $10^{4}$ cells/well) in Cell Culture Inserts with $0.4 \mu \mathrm{m}$ pores (BD Falcon) and osteoblasts $\left(1.0 \times 10^{4}\right.$ cells/well) in six-well plates (Cell Culture Insert Companion Plates, BD Falcon) in aMEM (ADSCs group). On the other hand, noncoculture was not established in any cells in Cell Culture Inserts and was established in osteoblasts only in six-well plates $\left(1.0 \times 10^{4}\right.$ cells/well) in aMEM (control group). After 3 days, ribonucleic acid (RNA) was extracted from rat osteoblasts of the ADSCs group noncontact cocultured with ADSCs and from the control group noncocultured osteoblasts.

\section{Total mRNA isolation}

We used a NucleoSpin1 RNA II kit (Takara Bio, Otsu, Japan) to extract RNA. We used a syringe to disrupt and homogenize each sample. Thereafter, we performed treatment according to the manufacturer's protocol, and measured the absorbance of the extracted total RNA at $260 \mathrm{~nm}$ with a Thermo Fisher Scientific NanoDrop Lite (Thermo Fisher Scientific, Waltham, MA, USA), and the concentration was calculated.

\section{cDNA synthesis}

We used $5 \times$ PrimeScript RT Master Mix (Perfect Real Time; Takara Bio) to synthesize cDNA. We performed treatment according to the manufacturer's protocol and adjusted it to a total volume of 20 $\mu \mathrm{L}$. We synthesized cDNA using a T100 Thermal Cycler (Bio-Rad Laboratories) under the following conditions: $37^{\circ} \mathrm{C}$ for 15 minutes, $85^{\circ} \mathrm{C}$ for 5 minutes, and $4^{\circ} \mathrm{C}$ hold.

\section{Real-time RT-PCR assays}

We added $2 \mu \mathrm{L}$ of the obtained cDNA sample, $10 \mu \mathrm{L}_{\text {SYBR }}^{\star}$ Premix Ex Taq II (Tli RNaseH Plus, Takara Bio), $0.8 \mu \mathrm{L}$ forward primer, 0.8 $\mu \mathrm{L}$ reverse primer, $0.4 \mu \mathrm{L}$ ROX Reference Dye $(50 \times)$, and $6 \mu \mathrm{L}$ RNAse free water (Takara Bio) to make a total volume of $20 \mu \mathrm{L}$. Primers for rat glyceraldehyde-3-phosphate dehydrogenase (GAPDH), bone morphogenetic protein-2 (BMP-2), and alkaline phosphatase-1 (ALP1) were purchased from Takara Biosystems. We performed reactions and amplification using an Applied Biosystems ${ }^{\otimes}$ StepOne $^{\mathrm{Tn}}$ Real-Time PCR System (Thermo Fisher Scientific) with 40 cycles at $95^{\circ} \mathrm{C}$ for 2 seconds and at $60^{\circ} \mathrm{C}$ for 30 seconds. We calculated the expression ratios of $B M P-2$ and $A L P-1$ to GAPDH for each sample, comparing the ADSCs and coculture groups.

\section{In vivo experiments}

The Institute for Experimental Animals, Kanazawa University Advanced Science Research Center approved the in vivo (animal model) experimental protocol. We performed surgery in accordance with the Guide for the Care and Use of Laboratory Animals published by the United States National Institutes of Health (NIH publication no. 85-23, revised 1996; Bethesda, MD), using aseptic techniques.

\section{Surgical procedure}

Ten-week-old Wistar rats (Japan SLC Co, Shizuoka, Japan) were assigned randomly to two groups (ADSCs and control groups). Each animal was anesthetized by intraperitoneal administration of 6.5 mg sodium pentobarbital (Somnopentyl1; Intervet, Tokyo, Japan), and placed in a lateral recumbent position on the operating table. A longitudinal skin incision on the lateral thigh was made over the left femur, and the quadriceps femoris and hamstrings were separated. The femoral shaft ( $8 \mathrm{~mm}$ long) was removed by osteotomy using a manual saw. The excised bone was frozen using liquid nitrogen and reimplanted by autologous bone transplantation, and intramedullary fixation was performed with a Kirschner wire (1.4 mm diameter; DePuy Synthes; Johnson \& Johnson, New Brunswick, NJ, USA). The ADSCs group received an addition of $0.1 \mathrm{~mL}$ Type I collagen gel (Atelocollagen; KOKEN, Tokyo, Japan) plus $5.0 \times 10^{6}$ ADSCs cells around the frozen bone. The control group was without ADSCs. Last, we sutured the fascia and skin and the rats were allowed movements without the limitation of weight bearing and external fixation in their cages after anesthesia.

\section{Histological examination}

Bone revitalization and union were evaluated through histological examination. Rats were euthanized 4 and 8 weeks postoperatively. The left total femurs were resected with the surrounding tissues and we fixed all specimens in $4 \%$ paraformaldehyde in PBS, $\mathrm{pH}$ 7.4. They were decalcified in $10 \%$ EDTA solution, were embedded in paraffin, were sectioned in the sagittal plane, and were stained with hematoxylin and eosin. We checked stained bone and the number of frozen bone revitalizations and host bone-frozen bone unions were compared. Furthermore, revitalization of frozen bone was assessed as the ratio of the number of lacunae with nucleated cells to that of whole lacunae according to a modification of a previously reported method, and this ratio was defined as the revitalization rate (Figure 1) [24]. Six fields at low magnification (objective lens $\times 10$ ) on a KEYENCE BZ-9000 microscope (Keyence Corporation, Osaka, Japan) from two proximal, two central, and two distal sites in frozen bone were selected in each specimen.

\section{DiI labeling}

We labeled ADSCs for tracking cells with a fluorescent lipophilic tracer 1,10-dioctadecyl-3,3,30,30-tetramethylindocarbocyanine perchlorate (DiI; MolecularProbes; Vybrant1 DiI Cell Labeling Solution; Life Technologies, Carlsbad, CA, USA). For labeling, we resuspended the cells at $1 \times 10^{6}$ cells $/ \mathrm{mL}$ in DMEM and added DiI at $5 \mathrm{~mL} / \mathrm{mL}$ in a medium without serum. After incubation for 20 minutes at $37^{\circ} \mathrm{C}$ with $5 \%$ humidified $\mathrm{CO}_{2}$, the cells were centrifuged at $1500 \mathrm{rpm}$ for $5 \mathrm{~min}$ utes and were washed twice with PBS, then were resuspended in Type I collagen gel (Atelocollagen; KOKEN) for addition around the frozen bone. We performed this examination to determine the location of $\mathrm{AD}$ SCs post-addition of ADSCs. A fresh frozen sagittal section of the left total femur was prepared using Kawamoto's method.

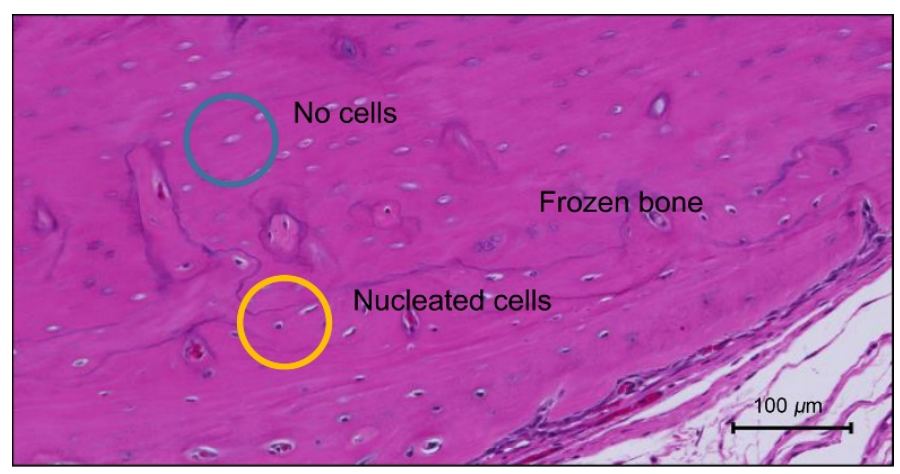

Figure 1. Photomicrographs of control group at 8 weeks. (Stain, hematoxylin and eosin magnification objective lens, $\times 10$ ). Revitalization of frozen bone was assessed as the ratio of the number of lacunae with nucleated cells to that of whole lacunae, and this ratio was defined as the revitalization rate 


\section{Statistical analysis}

We performed this as an observer-blinded study, and it was not different between each group. The experimental results were assessed as mean \pm standard error. We performed a $t$-test to compare the control and ADSCs groups in vitro and a Mann-Whitney's $U$ test in vivo. Differences were considered significant when $P$-value was $<0.05$.

\section{Results}

\section{Cell proliferation assays}

To ascertain the paracrine effect of ADSCs on osteoblasts, their cell viability was assessed using a conditioned culture method. The cell viability of osteoblasts in the ADSCs group was found to be higher than that in the control group ( $P=0.034$; Figure 2$)$.

\section{Western blotting assays}

A comparison between the phosphorylation ratios of Smad1 to total Smad1 showed the phosphorylation ratio to be higher in the ADSCs than in the control group $(P=0.027)$. Furthermore, comparison of c-Jun N-terminal kinase (JNK) and total JNK showed a higher phosphorylation ratio in the ADSCs than in the control group $(P=$ 0.021). This suggested that the conditioned culture of ADSCs enhanced the Smad and JNK pathways of the differentiation and osteogenesis signal of osteoblasts (Figure 3 ).

\section{Real-time RT-PCR assays}

The ADSCs group had lower BMP2 and ALP1 expression levels compared to the control group (expression ratios 0.184 and 1 , respectively; $P=0.039)$. The expression ratio of $A L P 1$ was 1 in the control group and 0.399 in the ADSCs group $(P=0.041$; Figure 4$)$.

\section{Histological examination}

In week 4 , bone revitalization was observed in two of five cases in the control group, and one of five in the ADSCs group. In week 8, bone revitalization was observed in two of five and five of five cases, respectively, suggesting an osteogenesis-promoting action of ADSCs in frozen bone. Revitalization rate was significantly higher in the ADSCs group than the control group. In week 4, the control group had a higher revitalization rate (4.2\%) compared to the ADSCs group (1.7\%); however, the difference was not significant $(P=0.602)$. In week 8 , the

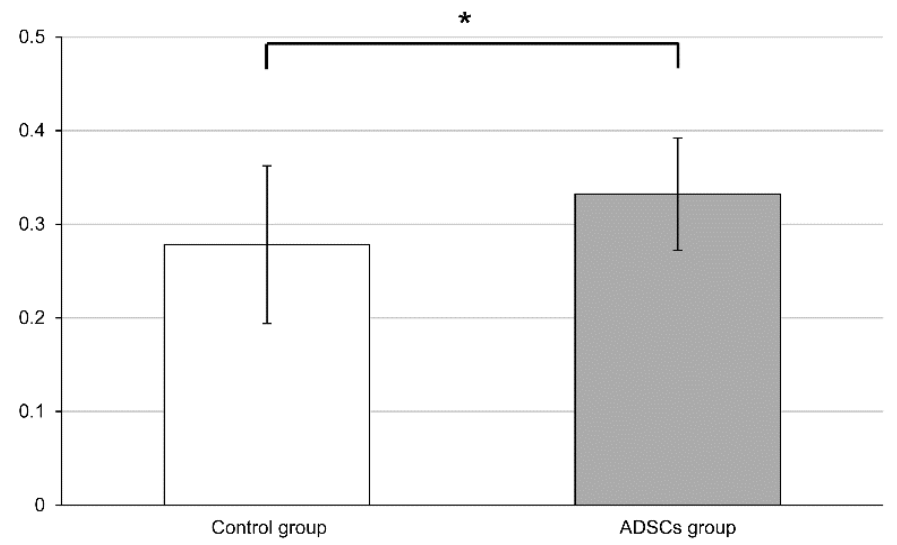

Figure 2. Cell proliferation assays for osteoblasts cultured with conditioned medium of osteoblasts (control group) and adipose-derived stem cells (ADSCs) (ADSCs group). The cell viability of osteoblasts in the ADSCs group was higher than that of osteoblasts in the control group $(P=0.034)$
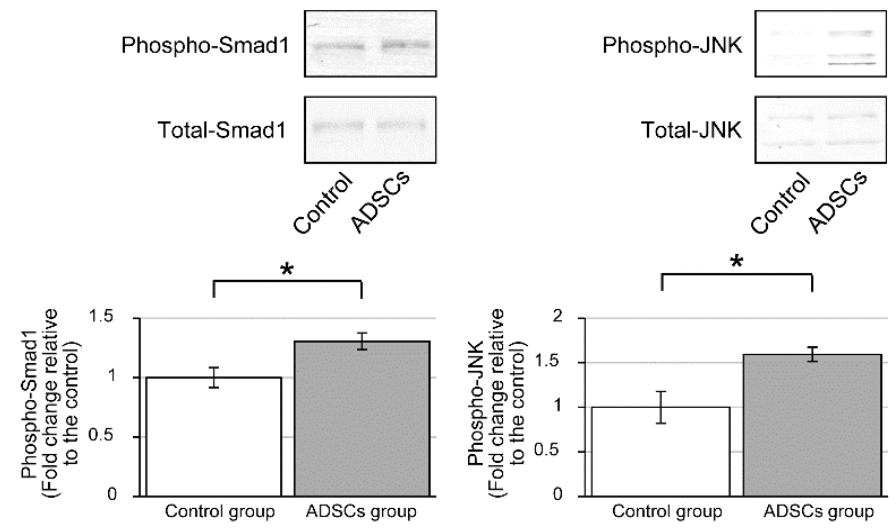

Figure 3. Western blotting assays for Smad1 and c-Jun N-terminal kinase (JNK) signal of osteoblasts cultured with conditioned medium of osteoblasts (control group) and adiposederived stem cells (ADSCs) (ADSCs group). A comparison between the phosphorylation ratios of Smad1 showed the phosphorylation rate to be higher in the ADSCs than in the control group $(P=0.027)$. Similarly, a comparison between the phosphorylation ratios of JNK showed a higher ratio in the ADSCs group than in the control groups $(P=0.021)$. This suggested that the conditional culture of ADSCs enhanced the Smad and JNK pathways of the differentiation and osteogenesis signal of osteoblasts

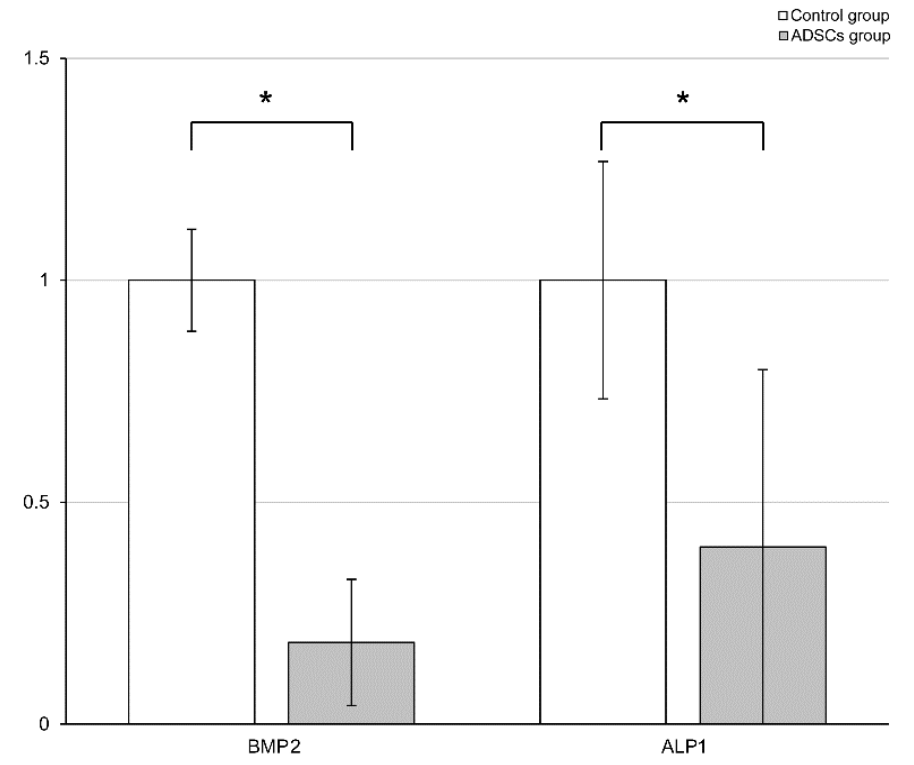

Figure 4. Real-time reverse transcription polymerase chain reaction (RT-PCR) assays for $B M P 2$ and $A L P 1$ osteoblast cocultured with rat adipose-derived stem cells (ADSCs) in noncontact coculture (ADSCs group) and noncocultured rat osteoblasts (control group). The ADSCs group had lower $B M P 2$ and $A L P 1$ expression levels compared with the control group using coculture method (expression ratio of $B M P 20.184$ versus 1, respectively; $P=$ 0.039 ). The expression ratio of $A L P 1$ was 1 in the control group and 0.399 in the ADSCs group $(P=0.041)$

ADSCs group had a higher revitalization rate $(24.8 \%)$ compared to the control group (5.1\%). This difference was significant $(P=0.0283$; Figure 5 and 6 ). In week 4 , bone union was not observed in the control and ADSCs groups. Bone union was observed in both groups in week 8; however, the difference was not significant.

\section{DiI labeling}

DiI labeling indicated that the transplanted cells had survived for 4 weeks after transplantation of ADSCs. DiI-positive region were detected during the 4 weeks after transplantation. Locally distributed transplanted cells were observed in soft tissue surrounding the frozen bone and not in the frozen or normal bone (Figure 7). 


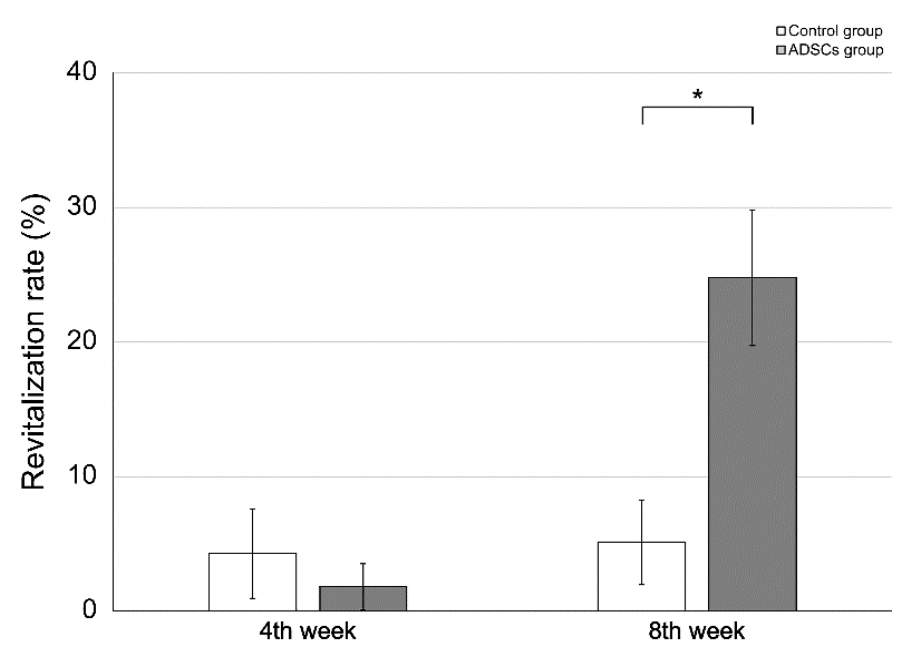

Figure 5. Histologic examination for revitalization ability of frozen bone with (adiposederived stem cells [ADSCs] group) and without (control group) ADSCs. Revitalization rate was significantly higher in the ADSCs group than the control group. At 4 weeks, the control group had a higher revitalization rate compared to the ADSCs group (revitalization rate, $4.22 \% \pm 3.33$ vs. $1.74 \% \pm 1.74$, respectively), but the difference was not significant $(P=0.602)$. At 8 weeks, the ADSCs group had a higher revitalization rate compared to the control group $(24.8 \% \pm 5.05$ vs. $5.10 \% \pm 3.14$, respectively), and this difference was significant $(P=0.0283$; Figure 6$)$
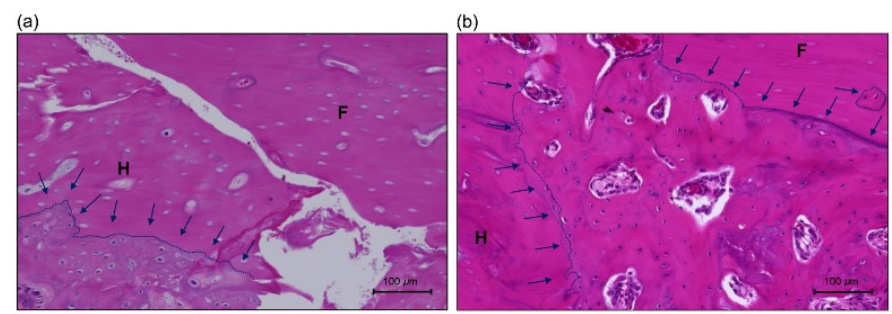

Figure 6. Photomicrographs of control and adipose-derived stem cells (ADSCs) groups at 8 weeks. (Stain, hematoxylin and eosin; magnification, objective lens $\times 10$ ). (a) In the contro group, although new bone from the host bone $(\mathrm{H})(\leftarrow)$ was observed, bone revitalization was not observed in the frozen bone $(\mathrm{F})$. The host bone $(\mathrm{H})$-frozen bone $(\mathrm{F})$ union was not observed. (b) In the ADSCs group, new bone from the host bone $(\mathrm{H})(\leftarrow)$ and bone revitalization were observed in the frozen bone $(\mathrm{F})(\leftarrow)$ and host bone $(\mathrm{H})$-frozen bone $(\mathrm{F})$ union was observed in the ADSCs group

\section{Discussion}

ADSCs have a faster cell proliferation rate and higher bone differentiation ability than BMSCs [25]. A cell proliferation assay using the conditioned culture method suggested that osteoblasts had increased cell proliferation capacity in the ADSCs proliferative environment, many ADSCs may produce much protein, and it was effective for osteoblasts of paracrine signaling. In this study, the humoral factors of ADSCs had a good effect on the bone environment; however, the paracrine effects of BMSCs were not confirmed for osteoblasts.

ADSCs secrete cytokines, such as BMP2, that contribute to the osteogenic activity of ADSCs [26]. There are two signaling pathways for BMP signaling. The main BMP signaling pathway is through receptor I-mediated phosphorylation of Smad1, Smad5, or Smad8 (R-Smad). The other BMP pathway is mediated by transforming growth factor- $\beta 1$ (TGF $\beta 1$ ) activated tyrosine kinase 1 (TAK1), and TAK1 can activate JNK $[27,28]$. Therefore, BMP not only activates the Smad signaling pathway, but also cooperatively activates the JNK signaling pathway. JNK activity is particularly required for late-stage differentiation events of osteoblasts [29]. JNK1 activation reduced the binding of inhibitory Smad6 to Type I BMP receptor and increased the binding of Smad1 to each other [30]. Both of these observations would enhance responsiveness to BMP2, and this pathway leads to increased cellular responsiveness [30]. Western blotting assays using the conditioned culture method in this study suggested that ADSCs led to significant acceleration in osteoblast differentiation, and real-time RT-PCR using the coculture method suggested that ADSCs led to significantly decreased expression of $B M P 2$ and $A L P 1$ produced by osteoblasts. One study reported an ALP increase and then a decrease as the cascade of the osteoblast differentiation proceeded [31]. Osteoblasts not cocultured with ADSCs produce much ALP, and ALP-produced osteoblasts cocultured with ADSCs were fewer than osteoblasts not cocultured with ADSCs. This comparison suggested that ADSCs accelerate osteoblast differentiation. As a paracrine effect of ADSCs, the activated Smad or JNK signaling pathway by BMP led to negative feedback resulting in reduction of BMP2 osteoblast production. The conditioned culture and coculture method studies suggested that ADSCs have paracrine effects of differentiation and osteogenesis of osteoblasts.

Although differentiation of mesenchymal stem cells (MSCs) transplanted locally contribute to part of the mechanism for the therapeutic effects, such as repair or regeneration, the survival and differentiation of MSCs is limited, and most of the therapeutic effect is paracrine signaling [32]. DiI labeling suggested that the transplanted ADSCs did not differentiate into bone but were focally distributed in soft tissue surrounding the frozen bone. ADSCs did not expand into autologous frozen bone but remained around the frozen bone by week 8. From the results of an in vitro study and DiI labeling, transplanted ADSCs had a paracrine effect that led to frozen autograft revitalization.

Nather et al. [33] reported that the addition of autologous BMSCs to frozen allograft improved bone union, new bone formation, and osteocyte cell counts. An in vivo study suggested that autologous frozen

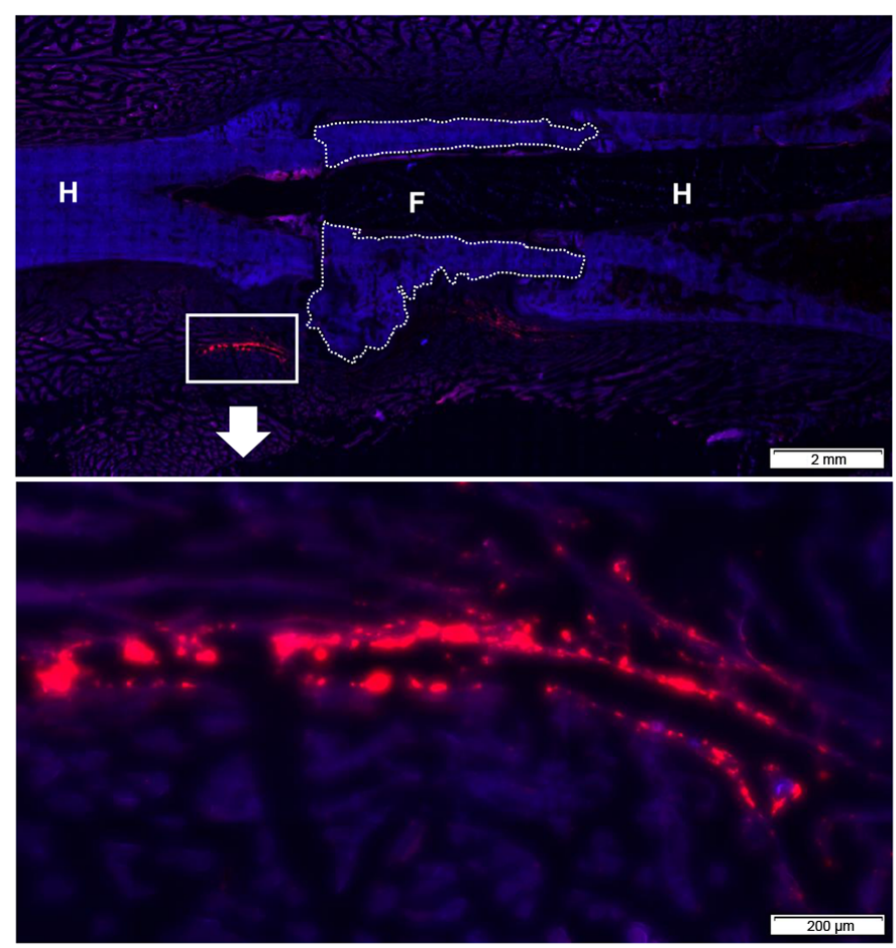

Figure 7. DiI labeling at 4 weeks after transplantation shows adipose-derived stem cells (ADSCs) labeled with DiI dye. This indicated that the transplanted cells had survived by 4 weeks. The distributions of DiI-positive (red) region were detected during the 4 weeks after transplantation. Locally distributed transplanted cells were observed in soft tissue surrounding the frozen bone and not in the frozen $(\mathrm{F})$ or host $(\mathrm{H})$ bone 
bone grafting of rat, in the control and ADSCs groups, showed bone revitalization ability at week 4 postoperatively. In our study, bone revitalization was significantly higher in the ADSCs group than in the control group at week 8 postoperatively. ADSCs have high bone forming and bone differentiation abilities at week 8 ; however, ADSCs did not demonstrate significant improvement of the host bone-frozen bone union. Nather et al. [33] used rabbits larger than the animals used in our study and they used plates for fixation of host bone-frozen bone. On the other hand, we used intramedullary fixation with a Kirschner wire, and the rats were allowed movements without the limitation of weight bearing and external fixation in their cages postoperatively. Therefore, postoperative load at the site of operation was not allowed. Intramedullary fixation of bone in our study was a bit weak and noload limit increased the bone junction's force point. If we used a much stronger fixation implant or load limit condition, the revitalization rate in week 4 would be changed. Kloeters et al. [34] reported on new vascularization and osteocyte proliferation of bone allograft by application of vascularized scaffolds seeded with osteogenic-induced ADSCs (O-ADSCs) induce. We have not confirmed O-ADSCs. Revitalization of frozen bone may be different from adding ADSCs and O-ADSCs. In addition, we used fewer animals in this study. Additional study using larger and more numbers of animals is required before clinical examination can be performed.

Recently, there were many reports of regeneration medicine using cell sheets. Uchihara et al. [35] reported that osteogenic matrix cell sheets' transplantation facilitated osteogenesis in irradiated rat bone. We reported that ADSCs sheets have better capability than separate ADSCs, which are not sheets, to be induced to differentiate into osteoblasts [15]. We used Type I collagen gel plus ADSCs cells around the frozen bone, and the transplanted cells were focally distributed in soft tissue surrounding the frozen bone. If we used the cell sheets, much transplanted cells might be distributed. We will try to study the ADSCs sheets.

Some studies have reported malignant tumor and ADSCs. ADSCs promote tumor growth in epithelial ovarian and breast cancers [36,37] or inhibit tumor growth in hepatocellular carcinoma and glioblastoma $[38,39]$. A relatively low proportion of ADSCs suppressed the growth of osteosarcoma, whereas high proportions showed a tumor-promoting effect [40]. Stromal ADSCs promote osteosarcoma progression and metastasis [41]. ADSC-secreted factors may not be involved in the risk of local recurrence [42]. It is unclear how ADSCs affect each tumor. There is no unified view. It is also necessary to evaluate the influence of ADSCs on malignant cells; for example, osteosarcoma or metastatic tumor cells to determine potential clinical applications. We examined the necrotic bone model using frozen autograft; however, we need to study the interaction of ADSCs with the tumor by the tumor bone model.

Various clinical trials have shown the regenerative capacity of stromal vascular fraction or ADSCs in medical subspecialties, such as cardiovascular disease, gastroenterology, plastic surgery, urology, orthopedic surgery, and so forth [43]. Some clinical trials were related to malignant tumor, especially breast cancer $[44,45]$. As reconstruction option after breast conservation therapy, adipose-derived regenerative cells were used for a prospective clinical trial, and no recurrences and no serious adverse events were reported [44]. Therefore, using ADSCs with frozen autograft after resection of malignant bone tumor may be a new reconstruction option.

\section{Conclusion}

In vitro, promotion of osteoblast proliferation and osteogenesispromoting action of ADSCs was confirmed. In vivo, the possibility of promoting frozen bone revitalization was also suggested and clinical application for reconstruction of bone defects after resection of malignant bone tumors is expected in the future.

\section{Acknowledgment}

The authors would like to thank Prof Yachie for his technical support to our experiments. This work was supported by a Grant-in-Aid for Scientific Research, JSPS KAKENHI [grant Number JP26462271, JP17K10962 (KH)] from K. Hayashi. We are grateful to Marybeth for carefully proofreading the manuscript.

\section{Conflicts of interest}

The authors indicate no potential conflicts of interest.

\section{References}

1. Tsuchiya H, Wan SL, Sakayama K, Yamamoto N, Nishida H, et al. (2005) Reconstruction using an autograft containing tumour treated by liquid nitrogen. $J$ Bone Joint Surg Br 87: 218-225.

2. Yamamoto N, Tsuchiya H, Tomita K (2003) Effects of liquid nitrogen treatment on the proliferation of osteosarcoma and the biomechanical properties of normal bone. $J$ Orthop Sci 8: 374-380.

3. Takata M, Sugimoto N, Yamamoto N, Shirai T, Hayashi K (2011) Activity of bone morphogenetic protein-7 after treatment at various temperatures: freezing vs. pasteurization vs. allograft. Cryobiology 63: 235-239.

4. Nishida H, Yamamoto N, Tanzawa Y, Tsuchiya H (2011) Cryoimmunology for malignant bone and soft-tissue tumors. Int J Clin Oncol 16: 109-117. [Crossref]

5. Igarashi K, Yamamoto N, Shirai T, Hayashi K, Nishida H, et al. (2014) The longterm outcome following the use of frozen autograft treated with liquid nitrogen in the management of bone and soft-tissue sarcomas. Bone Joint J 96: 555-561.

6. Tsuchiya H, Nishida H, Srisawat P, Shirai T, Hayashi K, et al. (2010) Pedicle frozen autograft reconstruction in malignant bone tumors. J Orthop Sci 15: 340-349.

7. Shimozaki S, Yamamoto N, Shirai T, Nishida H, Hayashi K, et al. (2014) Pedicle versus free frozen autograft for reconstruction in malignant bone and soft tissue tumors of the lower extremities. J Orthop Sci 19: 156-163.

8. Ashton BA, Allen TD, Howlett CR, Eaglesom CC, Hattori A, et al. (1980) Formation of bone and cartilage by marrow stromal cells in diffusion chambers in vivo. Clin Orthop Relat Res 3: 294-307. [Crossref]

9. Torres FC, Rodrigues CJ, Stocchero IN, Ferreira MC (2007) Stem cells from the fat tissue of rabbits: an easy-to-find experimental source. Aesthetic Plast Surg 31: 574578. [Crossref]

10. Seki A, Sakai Y, Komura T, Nasti A, Yoshida K, et al. (2013) Adipose tissue-derived stem cells as a regenerative therapy for a mouse steatohepatitis-induced cirrhosis model. Hepatology 58: 1133-1142.

11. Furuichi K, Shintani H, Sakai Y, Ochiya T, Matsushima K, et al. (2012) Effects of adipose-derived mesenchymal cells on ischemia-reperfusion injury in kidney. Clin Exp Nephrol 16: 679-689.

12. Nomura I, Watanabe K, Matsubara H, Hayashi K, Sugimoto N, Tsuchiya H, et al. (2014) Uncultured autogenous adipose-derived regenerative cells promote bone formation during distraction osteogenesis in rats. Clin Orthop Relat Res 472: 3798-3806.

13. Suganuma S, Tada K, Hayashi K, Takeuchi A, Sugimoto N, Ikeda K, et al. (2013) Uncultured adipose-derived regenerative cells promote peripheral nerve regeneration. J Orthop Sci 18: 145-151.

14. Kuroda K, Kabata T, Hayashi K, Maeda T, Kajino Y, et al. (2015) The paracrine effect of adipose-derived stem cells inhibits osteoarthritis progression. BMC Musculoskelet Disord 16: 236

15. Fang X, Murakami H, Demura S, Hayashi K, Matsubara H, et al. (2014) A nove method to apply osteogenic potential of adipose derived stem cells in orthopaedic surgery. PLoS One 19: e88874 
16. Toratani T, Nakase J, Numata H, Oshima T, Takata Y, Nakayama K, et al. (2017) Scaffold-free tissue-engineered allogenic adipose-derived stem cells promote meniscus healing. Arthroscopy 33: 346-354.

17. Kosaka M, Nakase J, Hayashi K, Tsuchiya H (2016) Adipose-derived regenerative cells promote tendon-bone healing in a rabbit model. Arthroscopy 32: 851-859.

18. Inatani H, Yamamoto N, Hayashi K, Kimura H, Takeuchi A, et al. (2017) Do mesenchymal stem cells derived from atypical lipomatous tumors have greater differentiation potency than cells from normal adipose tissues? Clin Orthop Relat Res 475:1693-1701.

19. Lee SW, Jeon TJ, Biswal S (2015) Fracture healing effects of locally-administered adipose tissue-derived cells. Yonsei Med J 56: 1106-1113.

20. Zuk PA, Zhu M, Mizuno H, Huang J, Futrell JW, et al. (2001) Multilineage cells from human adipose tissue: implications for cell-based therapies. Tissue Eng 7: 211-228.

21. Miwa S, Sugimoto N, Yamamoto N, Shirai T, Nishida H, Hayashi K, et al. (2012) Caffeine induces apoptosis of osteosarcoma cells by inhibiting AKT/mTOR/S6K, NF-B and MAPK pathways. Anticancer Res 32: 3643-3649.

22. Sugimoto N, Miwa S, Ohno-Shosaku T, Tsuchiya H, Hitomi Y, Nakamura H, et al. (2017) Hypoxia-induced inhibition of the endocannabinoid system in glioblastoma cells. Oncol Rep 38: 3702-3708.

23. Sugimoto N, Miwa S, Ohno-Shosaku T, Tsuchiya H, Hitomi Y, Nakamura H, et al. (2011) Activation of tumor suppressor protein PTEN and induction of apoptosis are involved in cAMP-mediated inhibition of cell number in B92 glial cells. Neurosci Lett 497: 55-59.

24. Nishida Y, Tsukushi S, Wasa J, Urakawa H, Toriyama K, Kamei Y, et al. (2011) Vascularized fibular flaps enhance histological repair in pasteurized autogenous bone graft. Ann Plast Surg 67: 416-420

25. Wyles CC, Houdek MT, Crespo-Diaz RJ, Norambuena GA, Stalboerger PG, et al. (2015) Adipose-derived Mesenchymal Stem Cells Are Phenotypically Superior for Regeneration in the Setting of Osteonecrosis of the Femoral Head. Clin Orthop Relat Res 473: 3080-3090.

26. Shoji T, Ii M, Mifune Y, Matsumoto T, Kawamoto A, Kwon SM, et al. (2010) Local transplantation of human multipotent adipose-derived stem cells accelerates fracture healing via enhanced osteogenesis and angiogenesis. Lab Invest 90: 637-649.

27. Derynck R, Zhang YE (2003) Smad-dependent and Smad-independent pathways in TGF-beta family signalling. Nature 425: 577-584. [Crossref]

28. Lee SW, Han SI, Kim HH, Lee ZH (2002) TAK1-dependent activation of AP-1 and c-Jun N-terminal kinase by receptor activator of NF-kappaB. J Biochem Mol Biol 35: 371-376. [Crossref]

29. Matsuguchi T, Chiba N, Bandow K, Kakimoto K, Masuda A, Ohnishi T, et al. (2009) JNK activity is essential for Atf4 expression and late-stage osteoblast differentiation. $J$ Bone Miner Res 24: 398-410.

30. Liu H, Liu Y, Viggeswarapu M, Zheng Z, Titus L, Boden SD, et al. (2011) Activation of c-Jun $\mathrm{NH}(2)$-terminal kinase 1 increases cellular responsiveness to BMP-2 and decreases binding of inhibitory Smad6 to the type 1 BMP receptor. $J$ Bone Miner Res 26: $1122-1132$.
31. Kim K, Dean D, Mikos AG, Fisher JP (2009) Effect of initial cell seeding density on early osteogenic signal expression of rat bone marrow stromal cells cultured on crosslinked poly(propylene fumarate) disks. Biomacromolecules 10: 1810-1817.

32. Hocking AM, Gibran NS (2010) Mesenchymal stem cells: paracrine signaling and differentiation during cutaneous wound repair. Exp Cell Res 316: 2213-2219.

33. Nather A, David V, Teng JW, Lee CW, Pereira BPs, et al. (2010) Effect of autologous mesenchymal stem cells on biological healing of allografts in critical-sized tibial defects simulated in adult rabbits. Ann Acad Med Singapore 39: 599-606. [Crossref]

34. Kloeters O, Berger I, Ryssel H, Megerle K, Leimer U, Germann G, et al. (2011) Revitalization of cortical bone allograft by application of vascularized scaffolds seeded with osteogenic induced adipose tissue derived stem cells in a rabbit model. Arch Orthop Trauma Surg 131: 1459-1466.

35. Uchihara Y, Akahane M, Shimizu T, Ueha T, Morita Y, Nakasaki S, et al. (2015) Osteogenic Matrix Cell Sheets Facilitate Osteogenesis in Irradiated Rat Bone. Biomed Res Int 155:629168. [Crossref]

36. Chu Y, Tang H, Guo Y, Guo J, Huang B, Fang F, et al. (2015) Adipose-derived mesenchymal stem cells promote cell proliferation and invasion of epithelial ovarian cancer. Exp Cell Res 337: 16-27

37. Kamat P, Schweizer R, Kaenel P, Salemi S, Calcagni M, Giovanoli P, et al. (2015) Human Adipose-Derived Mesenchymal Stromal Cells May Promote Breast Cancer Progression and Metastatic Spread. Plast Reconstr Surg 136: 76-84.

38. Zhao W, Ren G, Zhang L, Zhang Z, Liu J, Kuang P, et al. (2012) Efficacy of mesenchyma stem cells derived from human adipose tissue in inhibition of hepatocellular carcinoma cells in vitro. Cancer Biother Radiopharm 27: 606-613.

39. Pacioni S, D'Alessandris QG, Giannetti S, Morgante L, Coccè V, Bonomi A, et al (2017) Human mesenchymal stromal cells inhibit tumor growth in orthotopic glioblastoma xenografts. Stem Cell Res Ther 8: 53.

40. Lee SW, Jeon TJ, Biswal S (2015) Effect of local treatment with adipose tissue-derived mesenchymal stem cells in the early tumorigenesis of osteosarcoma. Oncol Rep 33:1381-1387.

41. Wang Y, Chu Y, Yue B, Ma X, Zhang G, Xiang H, et al. (2017) Adipose-derived mesenchymal stem cells promote osteosarcoma proliferation and metastasis by activating the STAT3 pathway. Oncotarget 8: 23803-23816

42. Avril P, Le Nail LR, Brennan MA, Rosset P, De Pinieux G, Layrolle P, et al. (2015) Mesenchymal stem cells increase proliferation but do not change quiescent state of osteosarcoma cells: Potential implications according to the tumor resection status. $J$ Bone Oncol 5: 5-14.

43. Gimble JM, Bunnell BA, Guilak F (2012) Human adipose-derived cells: an update on the transition to clinical translation. Regen Med 7: 225-235.

44. P Perez-Cano R, Vranckx JJ, Lasso JM, Calabrese C, Merck B, Milstein AM, et al (2012) Prospective trial of adipose-derived regenerative cell (ADRC)-enriched fat grafting for partial mastectomy defects: the RESTORE-2 trial. Eur J Surg Oncol 38: 382-389.

45. Rigotti G, Marchi A, Galie M, Baroni G, Benati D, Krampera M, et al. (2007) Clinical treatment of radiotherapy tissue damage by lipoaspirate transplant: a healing process mediated by adipose-derived adult stem cells. Plast Reconstr Surg 119: 1409-1422.

Copyright: (C2019 Aoki Y. This is an open-access article distributed under the terms of the Creative Commons Attribution License, which permits unrestricted use, distribution, and reproduction in any medium, provided the original author and source are credited. 